\title{
PERANCANGAN DAN PENGUKURAN KINERJA VIDEO STREAMING MENGGUNAKAN RED5 PADA MESIN VIRTUAL
}

\author{
Yuli Christyono*), Imam Santoso, and Ajub Ajulian Zahra \\ Departemen Teknik Elektro, Fakultas Teknik, Universitas Diponegoro, \\ Jl. Prof. Sudharto, SH, Kampus UNDIP Tembalang, Semarang 50275, Indonesia \\ ${ }^{*}$ E-mail : mrjully@gmail.com
}

\begin{abstract}
Abstrak
Aplikasi multimedia menjadi sangat dibutuhkan seiring dengan meningkatnya penggunaan internet. Salah satu layanan yang sangat menarik untuk diterapkan adalah video streaming. Video streaming yang bersifat live streaming juga dapat digunakan untuk memantau suatu lokasi tertentu atau berperan sebagai CCTV. Pada penelitian ini aplikasi Red5 digunakan untuk merealisasikan suatu sistem layanan video streaming menggunakan virtual server. Selanjutnya kinerja layanan akan dianalisis apakah layanan tersebut layak diterapkan atau tidak. Layanan ini terdiri dari beberapa komponen yaitu sumber, server Red5, dan klien. Sumber berperan sebagai encoder,untuk mengubah data-data yang ditangkap dari alat penangkap. Server Red5 memiliki 2 fungsi utama, yaitu menerima stream dari sumber dan mengirim stream video yang terdapat pada server, sehingga pengguna dapat mengakses hasil stream tersebut melalui perangkat klien. Aplikasi klien berupa web untuk menjalankan dan menampilkan layanan video streaming. Hasil pengujian menunjukkan layanan video streaming berjalan dengan baik. Pengujian menggunakan empat skenario layanan dan diperoleh nilai tundaan tertinggi $195,09 \mathrm{~ms}$, sedangkan penggunaan terbaik dengan nilai tundaan terendah adalah 10,37 ms. Nilai packet loss tertinggi 5,22 \%, dan terendah adalah $0 \%$. Nilai luaran tertinggi $0,82 \mathrm{Mbps}$ dan terendah adalah 0,06 Mbps. Nilai tundaan, packet loss dan luaran masih dalam kategori baik dan memenuhi standar berdasarkan ITU-T G1010..
\end{abstract}

Keyword : Red5,Video streaming, mesin virtual, web, ITU-T G1010.

\begin{abstract}
Multimedia applications become indispensable along with the increasing use of the internet. One of the most interesting services or apps to implement is streaming video. Streaming video can also be used to monitor a particular location or act as CCTV. In this research the Red5 is used to realize a streaming video service system using virtual server. Furthermore, service performance will be analyzed. This service consists of several components ie publisher, Red5 server, and client. The publisher acts as an encoder, to change the captured data from the capture device. Red5 server has two main functions, which receive stream from the publisher and send video stream contained on server, so that user can access the result stream through client device. Then web client application runs and display video streaming service.The test used four service scenarios and obtained the highest delay of $195.09 \mathrm{~ms}$, while the lowest delay was $10.37 \mathrm{~ms}$. The highest packet loss is $5.22 \%$, and the lowest is $0 \%$. The highest output at the time of testing was 0.82 Mbps and the lowest was $0.06 \mathrm{Mbps}$. The value of delay, packet loss and output is still in good category and meets the standards based on ITU-T G1010.
\end{abstract}

Keywords : Red5, video streaming, CCTV, virtual server, web, ITU-T G1010.

\section{Pendahuluan}

Penggunaan internet sekarang ini semakin meningkat, suatu aplikasi multimedia menjadi sangat dibutuhkan. Hal ini dapat dilihat dari semakin beragamnya penyampaian informasi yang tidak hanya berupa teks, tetapi juga meliputi suara, data, gambar maupun video.

Salah satu layanan atau aplikasi yang sangat menarik untuk diterapkan adalah video streaming yang menjadi salah satu layanan yang paling banyak digunakan oleh kebanyakan orang. Penerapan teknologi video streaming menjadi solusi baru dalam penyampaian multimedia berbasis jaringan.

Video streaming juga dapat digunakan untuk memantau suatu lokasi tertentu atau berperan sebagai CCTV. Video streaming sebagai CCTV ini merupakan salah satu aplikasi video streaming yang bersifat live streaming yang memungkinkan suatu lokasi dapat terpantau dan didistribusikan melalui jaringan Internet atau lokal secara langsung. 
Beberapa penelitian mengenai video streaming sudah banyak dilakukan, diantaranya adalah penggunaan teknologi video streaming berbasis Red5 server dalam aplikasi Internet-TV [1]. Selanjutnya aplikasi Video streaming menggunakan HTML 5.0 ${ }^{[2]}$, Virtual Local Area Network untuk Komunikasi Video Streaming dan Suara $^{[3]}$. Sedangkan penelitian mengenai server dan mesin virtual juga sudah dilakukan, diantaranya penggunaan mesin virtual VMWARE untuk optimalisasi server ${ }^{[4]}$ dan perbandingan kinerja server Red5 dan Darwin Streaming Server ${ }^{[5]}$.

Pada penelitian ini mesin virtual yang digunakan adalah Proxmox $^{[6]}$ dan Server menggunakan Red5 yang merupakan server open source. Selanjutnya untuk mengukur kinerja layanan video streaming digunakan jaringan local (LAN). Pengguna menggunakan web browser untuk mengakses layanan tersebut.

Tahapan perancangan sampai dengan realisasi dapat dilihat seperti Gambar 1 di bawah ini.

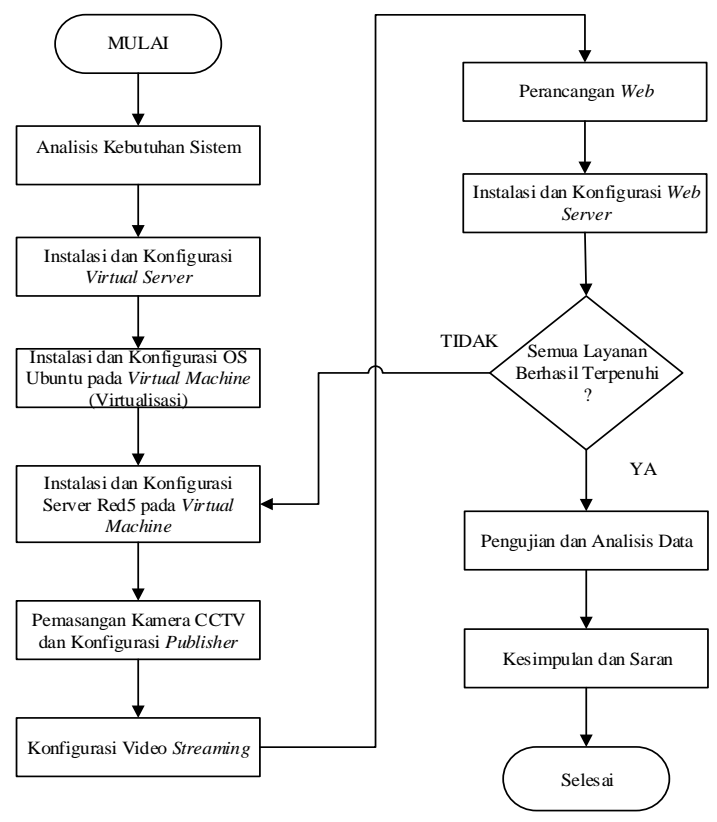

Gambar 1 Diagram alir Perancangan

Penelitian ini disusun dengan beberapa komponen seperti pada Gambar 2 di bawah ini.



Gambar 2 Komponen Sistem

- Sumber berperan sebagai encoder, untuk mengubah data-data yang masuk dari alat penangkap (video/audio). Sumber juga dapat melakukan perekaman video hasil tangkapan dari alat penangkap tersebut.
- Server Red5 memiliki dua fungsi utama, yang pertama berfungsi untuk menerima stream dari sumber, sedangkan yang kedua berfungsi untuk mengirimkan stream video yang terdapat pada server, sehingga video tersebut dapat diakses klien.

- Klien merupakan sisi pengguna, yang menampilkan Flash movie yang merupakan hasil stream dari server Red5.

\section{Metode}

Perangkat yang digunakan dalam perancangan sistem dibagi dalam dua jenis, yaitu perangkat keras dan perangkat lunak. Perangkat lunak Server Red5 berada dalam satu komputer server dengan menggunakan sistem operasi Ubuntu 12.04 yang dipasang pada perangkat lunak Proxmox yang merupakan sebuah perangkat virtualisasi server. Perangkat keras yang digunakan dapat dilihat pada Gambar 3 di bawah ini.

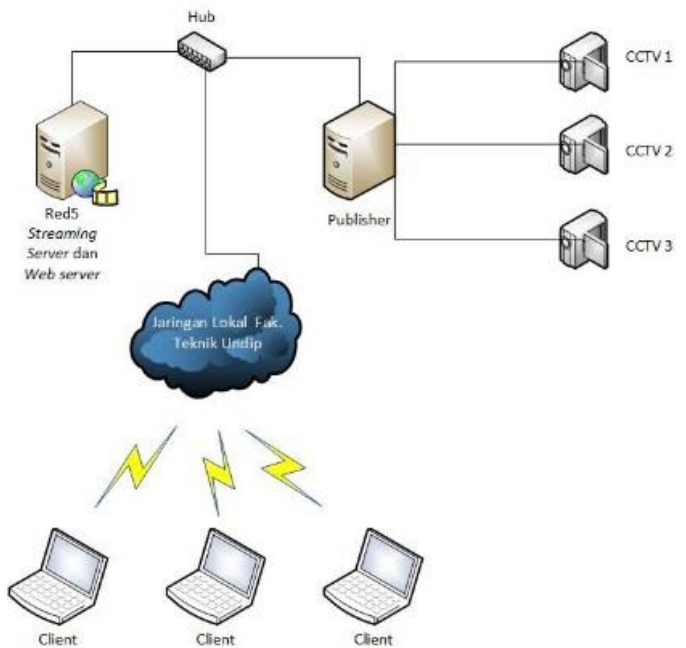

Gambar 3. Komponen Perangkat Keras

\subsection{Instalasi dan Konfigurasi Proxmox}

Proxmox bersifat open source berfungsi untuk menjalankan mesin virtual berbasis KVM berupa sistem operasi Linux yang nantinya digunakan sebagai server Red5 dengan layanan video streaming.

Beberapa tahap yang penting dan perlu diperhatikan pada proses instalasi adalah proxmox akan menggunakan seluruh ruang penyimpanan yang ada, pembuatan partisi akan ditangani secara otomatis dan ruang penyimpanan yang digunakan diformat total, maka perlu diperhatikan untuk mem-backup dahulu data sebelum memulai instalasi, tahap yang kedua yang perlu diperhatikan adalah mengatur password untuk user root yang digunakan untuk mengakses web administrator, tahap ketiga adalah pengaturan jaringan (IP address, netmask, gateway). 
Proses virtualisasi di Proxmox dilakukan melalui web browser dengan mengakses alamat IP dari Proxmox yang sudah dikonfigurasi sebelumnya dan akan dibuat virtualisasi berupa sistem operasi Linux yang nantinya digunakan sebagai server Red5 dengan layanan video streaming.

\subsection{Instalasi dan Konfigurasi Server Red5}

Instalasi server Red5 dilakukan pada sistem operasi Linux 12.04 yang terpasang pada mesin virtual server Proxmox yang telah diinstal dan dikonfigurasi sebelumnya. Sebelum proses instalasi dan konfigurasi, terlebih dahulu dilakukan konfigurasi IP di Linux dan menetukan IP yang digunakan untuk koneksi ke jaringan lokal atau internet.

Beberapa komponen perangkat lunak penting yang dibutuhkan sebagai pendukung dari server Red5 adalah paket-paket Java, Ant yang digunakan untuk proses kompilasi dan membangun kelas-kelas Java, dan juga subversion. Server Red5 menggunakan framework Java sehingga komponen-komponen pendukung tersebut sangat dibutuhkan.

Server Red5 menggunakan Flash oleh karena itu diperlukan juga plugin Flash yang terpasang baik pada sisi server maupun pada sisi client. Tahap selanjutnya adalah proses instalasi server Red5. Agar server Red5 dapat berjalan secara otomatis pada saat booting atau saat reboot, maka perlu dilakukan pembuatan file skrip init untuk Red5 di direktori /etc/init.d.

\subsection{Konfigurasi Sumber}

Sumber berperan sebagai encoder yaitu untuk mengubah data-data yang ditangkap dari alat penangkap (video/audio device) menjadi format file lain yang dapat diteruskan ke server Red5, dan server Red5 yang akan mempublikasikan data-data stream tersebut. Dalam penelitian ini digunakan kamera USB Webcam sebagai alat penangkap video dan data-data video diubah menjadi Flash video. USB Webcam diposisikan sebagai kamera CCTV dan ditempatkan di lokasi-lokasi yang akan dipantau..

Setelah konfigurasi selesai dan sumber sudah terhubung dengan server Red5 maka layanan CCTV sudah bisa dipublish. Terdapat 3 tipe publish yang dapat dipilih yaitu live apabila sumber hanya menampilkan video secara langsung tanpa melakukan perekaman, record dan append apabila sumber menampilkan video secara langsung sekaligus melakukan perekaman. Hasil perekaman video tersimpan dalam folder /usr/share/red5/webapps/ oflademo/streams yang terdapat pada PC server. Berikut ini tampilan sumber seperti yang terlihat pada Gambar 4 di bawah ini.

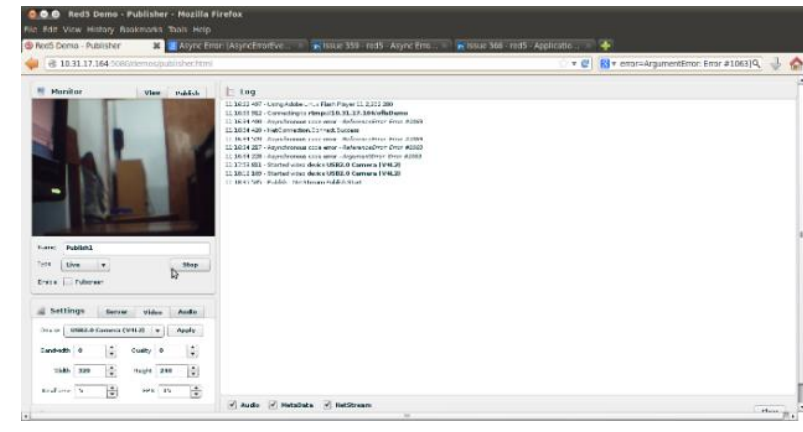

\section{Gambar 4. Publisher}

\subsection{Konfigurasi Video Streaming}

Untuk layanan video streaming konfigurasi dilakukan dengan menambahkan file-file video yang ingin distreaming-kan dan disimpan dalam folder /usr/share/red5/webapps/oflademo/streams yang terdapat pada PC server. Penambahan file-file video pada penelitian ini dilakukan dengan menggunakan program WinSCP yang merupakan SFTP, SCP, dan FTP klien untuk Windows. WinSCP memungkinkan transfer file secara aman antara komputer lokal dengan virtual server. Format file video yang dapat dimainkan pada layanan video streaming yaitu flv, mp4, dan mov.

\subsection{Perancangan $\mathrm{Web}$}

Web digunakan pada sisi klien agar dapat menjalankan layanan video streaming. Klien dapat menggunakan layanan video streaming dengan mengakses web browser dari PC atau laptop yang terhubung dengan jaringan, dan web browser tersebut harus terpasang plugin Flash. Selanjutnya klien membuka alamat URL dari web yang digunakan untuk menampilkan layanan video streaming.

Perancangan web dilakukan dengan membuat layout web dan selanjutnya membuat halaman web berdasarkan layout web yang sudah dibuat ke dalam skrip-skrip dengan menggunakan HTML (HyperText Markup Language) dan CSS (Cascading Style Sheet).

Halaman web yang dibuat dalam perancangan web ini ada 2 yaitu halaman untuk layanan CCTV dan video streaming. Untuk membuat halaman web CCTV dibuat skrip HTML yang disimpan dan diberi nama index.html, dan agar halaman web yang ditulis dalam dokumen HTML tersebut lebih teratur dan menarik tampilannya maka diperlukan sentuhan CSS. Berikutnya adalah halaman web layanan video streaming, untuk membuat halaman web video streaming yang disimpan dan diberi nama webvideo.html dan dengan skrip CSS yang disimpan dan diberi nama styles2.css.

Web harus dapat terhubung dengan server Red5 agar web dapat menampilkan dan menjalankan layanan video 
streaming dan CCTV, untuk itu diperlukan Flash media player yang sudah mendukung streaming RTMP. Web ini menggunakan Flash media player JWPlayer yang dipasang bersama dengan skrip-skrip HTML dan CSS di web server untuk dapat menampilkan streaming RTMP dari server Red5.

Skrip-skrip HTML disisipkan skrip dari media player yang nantinya akan menghubungkan web dengan server Red5. Skrip media player disisipkan di dalam tag 〈head > seperti berikut ini :

<script type="text/javascript" src= "jwplayer.js" $></$ script $>$

\subsection{Instalasi Web Server dan Upload Komponen Web ke Dalam Web Server}

Perancangan web selanjutnya adalah proses instalasi web server, agar web bisa berjalan dan ditampilkan pada web browser PC klien. Web server menggunakan platform open source yaitu Apache yang dibundel dalam LAMPP (Linux Apache MySQL PHP Perl). Web server dipasang pada PC server sistem operasi Linux bersamaan dengan server Red5 yang sudah terhubung ke jaringan.

\section{Hasil dan Analisa \\ 3.1. Pengujian Layanan Web}

Pengujian dilakukan pada web sebagai aplikasi klien layanan video streaming yang fungsinya untuk menjalankan dan menampilkan layanan video streaming. Pengujian ditujukan untuk menguji setiap komponen layanan yaitu video streaming dan CCTV untuk mengetahui apakah sistem telah bekerja sesuai dengan perancangan dan konfigurasi yang telah diberikan. Pengujian dilakukan dengan mengakses alamat URL dari web layanan video streaming yaitu 10.31.17.164/webcctv/. Pengujian yang dilakukan adalah sebagai berikut :

1. Pengujian halaman web layanan CCTV

Halaman layanan CCTV dengan skrip index.html merupakan halaman awal yang pertama kali tampil ketika client mengakses web layanan video streaming dan CCTV dengan alamat URL 10.31.17.164/webcctv/. Halaman ini digunakan untuk melihat hasil pantauan video secara langsung yang ditangkap dari kamera CCTV yang terhubung dengan komputer sumber, kemudian hasil tangkapan tersebut diteruskan ke server Red5. Server Red5 yang tugasnya mengirim hasil stream tersebut ke klien dan ditampilkan melalui Flash player yang ada pada halaman web ini. Terdapat tiga layar video yang ditampilkan pada halaman ini yang merupakan tiga pantauan video langsung dari tiga lokasi yang berbeda.

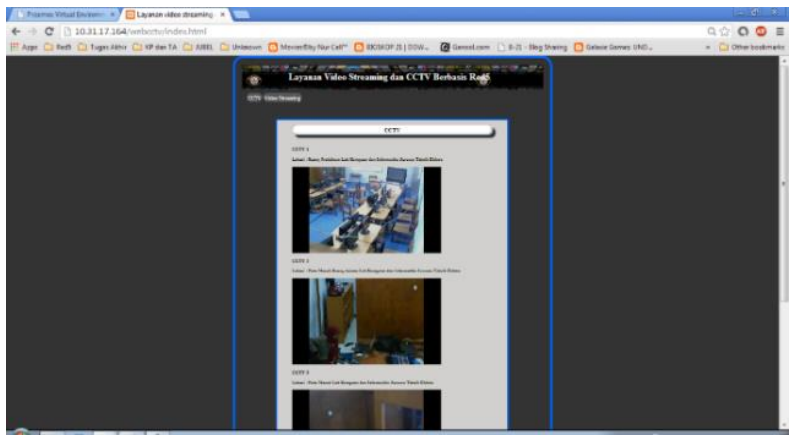

Gambar 5. Tampilan halaman web layanan CCTV.

Gambar 5 menampilkan halaman web layanan CCTV yang menjadi halaman awal ketika klien mengakses web layanan video streaming. Di dalam halaman ini terdapat dua menu navigasi yaitu CCTV dan Video Streaming. Terlihat bahwa tiga layar menampilkan video hasil tangkapan kamera CCTV di tiga lokasi, kamera CCTV tersebut terhubung dengan komputer sumber. Video yang ditampilkan pada halaman ini merupakan hasil stream dari server Red5 yang terhubung dengan halaman web layanan CCTV.

2. Pengujian halaman web layanan video streaming Halaman layanan video streaming dengan skrip webvideo.html merupakan halaman yang digunakan untuk menampilkan video yang tersimpan pada server Red5. Server Red5 akan mengirimkan streaming video tersebut sesuai dengan permintaan dari klien sehingga klien dapat memainkan dan menonton video streaming tersebut melalui Flash Player yang ada pada halaman web. Pada halaman ini juga terdapat Playlist yang berisi kumpulan video yang dapat dimainkan dan dipilih oleh client. Gambar 6 menunjukkan tampilan dari halaman layanan video streaming.

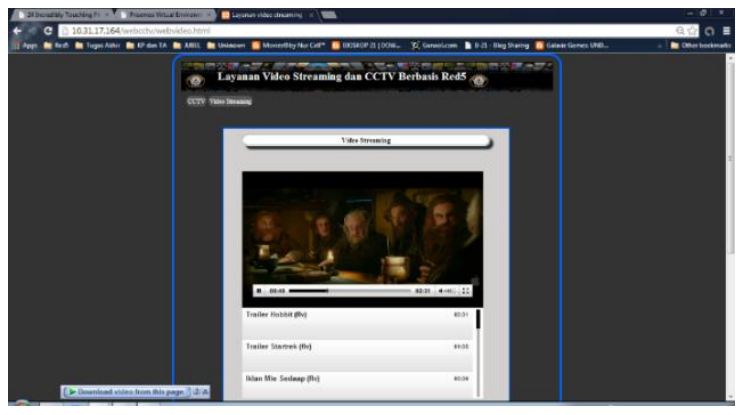

Gambar 6. Tampilan halaman web layanan video streaming

Format file video yang dapat dimainkan pada layanan video streaming adalah flv, mp4, dan mov.

\subsection{Pengujian Kualitas Layanan}

Pengujian kualitas layanan video streaming dilakukan untuk mengukur aspek-aspek Quality of Service (QoS) 
yang terdiri dari pengukuran delay (waktu tunda), packet loss (kerugian paket), dan nilai throughput. Hal ini dilakukan untuk mengetahui kualitas dari layanan /sesuai dengan standar ITU-T G.1010. Untuk jitter tidak dilakukan pengukuran karena pada standar ITU-T G.1010 nilai jitter untuk aplikasi video tidak diketahui.

Pengujian layanan dilakukan dengan menerapkan beberapa rangkaian skenario penggunaan layanan. Pengujian dilakukan pada sisi server, wireshark mencatat arus pertukaran data yang terjadi antara server dengan clients setiap kali penggunaan layanan dilakukan kemudian mengetahui nilai dari parameter Quality of Service (QoS) yang diuji yaitu nilai delay, packet loss dan throughput. Beberapa rangkaian skenario penggunaan layanan sebagai berikut :

1. Penggunaan layanan dengan beberapa pengguna aktif Gambar 7 menunjukkan grafik hasil pengukuran delay pada penggunaan layanan dengan beberapa pengguna aktif.

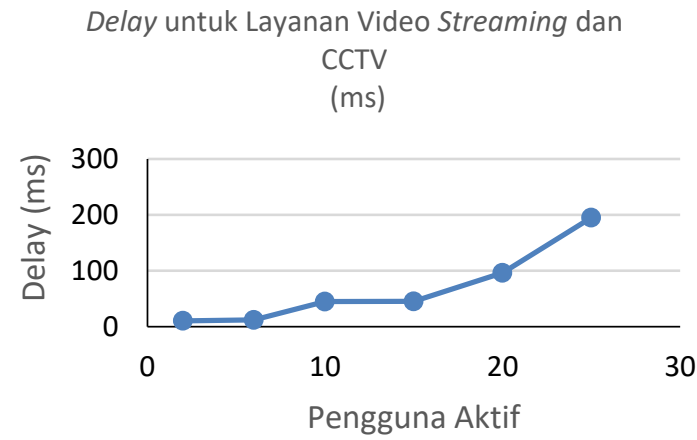

\section{Gambar 7. Grafik pengukuran delay}

Standar nilai delay untuk aplikasi video satu arah berdasarkan ITU-T G.1010 adalah tidak lebih besar dari $10 \mathrm{~s}$. Berdasarkan hasil pengukuran, terlihat dari grafik bahwa nilai delay pada penggunaan layanan dengan beberapa pengguna aktif masih dalam kategori baik dan memenuhi standar delay berdasarkan ITU-T G.1010. Dari gambar grafik terlihat semakin banyak jumlah pengguna aktif maka nilai delay semakin tinggi, nilai delay tertinggi yaitu pada saat penggunaan layanan dengan 25 pengguna aktif sebesar 195,09 ms, sementara penggunaan terbaik dengan nilai delay terendah adalah pada saat penggunaan layanan dengan 2 pengguna aktif sebesar $10,37 \mathrm{~ms}$.

Gambar 8 menunjukkan grafik hasil pengukuran packet loss pada penggunaan layanan dengan beberapa pengguna aktif.

\section{Packet Loss untuk Layanan Video Streaming dan CCTV}

(\%)

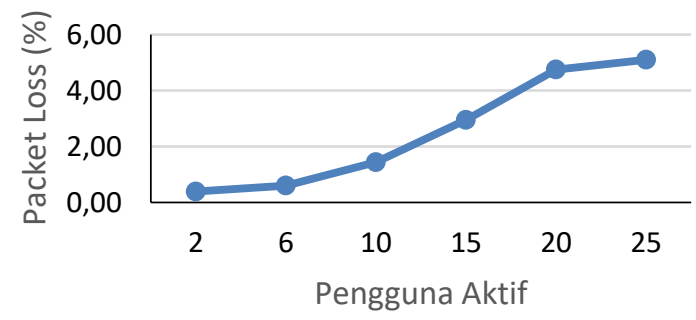

\section{Gambar 8. Grafik pengukuran packet loss}

Standar nilai packet loss untuk aplikasi video satu arah berdasarkan ITU-T G.1010 adalah tidak lebih besar dari $1 \%$. Berdasarkan hasil pengukuran, nilai packet loss pada penggunaan layanan dengan beberapa pengguna aktif masih dalam kategori baik dan memenuhi standar packet loss berdasarkan ITU-T G.1010 ketika dilakukan pengukuran pada 2 sampai 6 pengguna aktif. Sedangkan nilai packet loss untuk 10 sampai 25 pengguna aktif melebihi standar nilai packet loss. Terlihat pada grafik, semakin banyak jumlah pengguna aktif maka nilai packet loss semakin tinggi, nilai packet loss tertinggi yaitu pada saat penggunaan layanan dengan 25 pengguna aktif sebesar $5,10 \%$, sementara penggunaan terbaik dengan nilai packet loss terendah adalah pada saat penggunaan layanan dengan 2 pengguna aktif sebesar $0,39 \%$.

Gambar 9 menunjukkan grafik hasil pengukuran throughput pada penggunaan layanan dengan beberapa pengguna aktif.

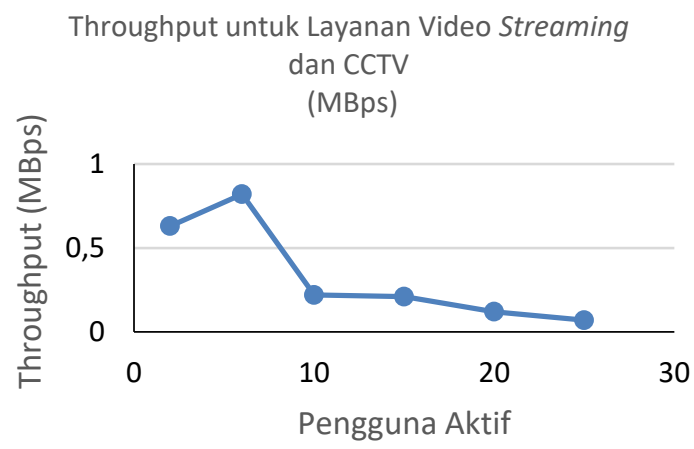

Gambar 9. Grafik pengukuran throughput

Berdasarkan hasil pengukuran, terlihat nilai throughput pada penggunaan layanan dengan beberapa pengguna aktif. Grafik menampilkan adanya penurunan nilai throughput ketika jumlah pengguna aktif bertambah dari 6 sampai 25 pengguna aktif. Namun pada penggunaan layanan dengan 2 sampai 5 pengguna aktif terjadi ketidaksesuaian dimana 
seharusnya nilai throughput nya lebih besar, dikarenakan dengan jumlah pengguna yang meningkat maka nilai throughput seharusnya akan semakin menurun. Hal ini disebabkan oleh sejumlah faktor yang terjadi pada saat pengukuran seperti penurunan signal jaringan dalam media jaringan lokal, dan juga terjadi trafik tinggi sehingga beban jaringan lebih besar pada saat pengukuran. Nilai throughput tertinggi yaitu pada saat penggunaan layanan dengan 6 pengguna aktif sebesar $0,82 \mathrm{Mbps}$, sementara penggunaan dengan nilai throughput terendah adalah pada saat penggunaan layanan dengan 25 pengguna aktif sebesar 0,07 Mbps.

2. Penggunaan layanan pada waktu-waktu tertentu Gambar 10 menunjukkan grafik hasil pengukuran delay pada penggunaan layanan pada waktu-waktu tertentu.

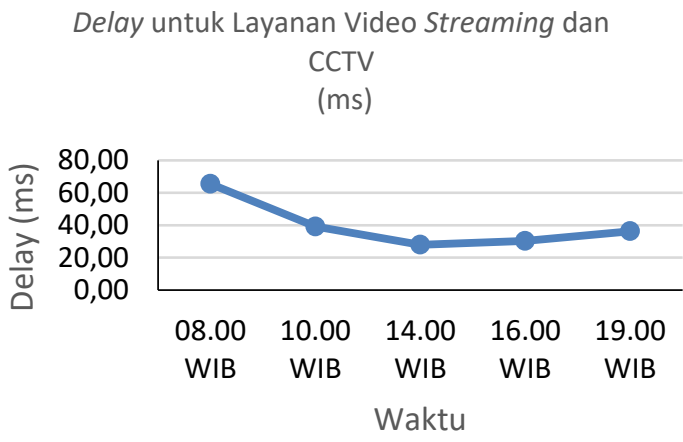

\section{Gambar 10. Grafik pengukuran delay waktu tertentu}

Berdasarkan hasil pengukuran, terlihat nilai delay pada penggunaan layanan pada waktu-waktu tertentu masih dalam kategori baik dan memenuhi standar delay. Nilai delay tertinggi yaitu pada saat pengukuran pada jam 08.00 WIB sebesar $65,43 \mathrm{~ms}$, hal ini terjadi karena pada jam tersebut merupakan jam dimulainya kegiatan kampus sehingga trafik tinggi pada jam tersebut. Semakin siang nilai delay menurun, penggunaan terbaik dengan nilai delay terendah adalah jam 14.00 WIB sebesar 27,94 ms dan kembali naik pada saat sore dan malam hari karena pada saat sore dan malam hari banyak terjadi aktifitas unduh data. Gambar 11 menunjukkan grafik hasil pengukuran packet loss pada penggunaan layanan pada waktuwaktu tertentu.

\section{Packet Loss untuk Layanan Video Streaming dan CCTV}

(\%)

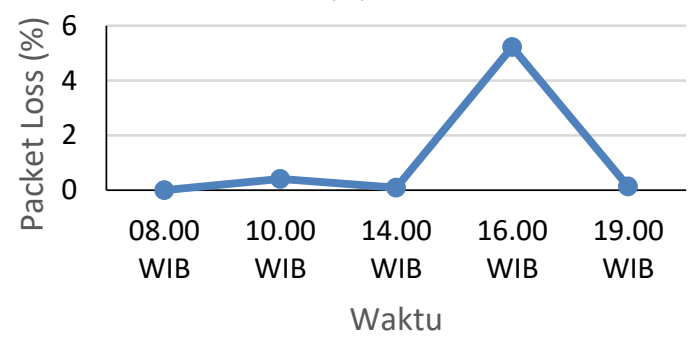

\section{Gambar 11. Grafik pengukuran packet loss waktu tertentu}

Berdasarkan hasil pengukuran, terlihat dari grafik bahwa nilai packet loss pada penggunaan layanan pada waktu-waktu tertentu masih dalam kategori baik dan memenuhi standar ketika dilakukan pengukuran pada jam 08.00 WIB, 10.00 WIB, 14.00 WIB dan 19.00 WIB. Sedangkan nilai packet loss pada jam 16.00 WIB melebihi standar nilai packet loss. Hal ini disebabkan oleh sejumlah faktor yang terjadi pada saat pengukuran seperti penurunan signal jaringan dalam media jaringan lokal, dan juga terjadi trafik tinggi sehingga beban jaringan lebih besar. Dari hasil pengukuran nilai packet loss didapat hasil yang tidak sesuai dengan hasil pengukuran delay, nilai packet loss tertinggi yaitu pada saat penggunaan layanan pada jam 16.00 WIB sebesar 5,22 \%, sementara penggunaan terbaik dengan nilai packet loss terendah adalah pada saat penggunaan layanan pada jam 14.00 WIB sebesar $0,09 \%$.

Gambar 12 menunjukkan grafik hasil pengukuran throughput pada penggunaan layanan pada waktuwaktu tertentu.

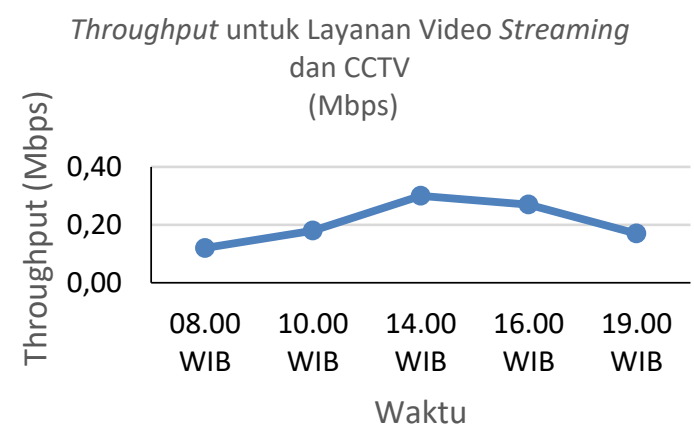

Gambar 12. Grafik pengukuran throughput waktu tertentu 
Berdasarkan hasil pengukuran, terlihat nilai throughput pada penggunaan layanan pada waktuwaktu tertentu. Nilai throughput tertinggi yaitu pada saat jam 14.00 WIB sebesar 0,30 Mbps, sementara penggunaan dengan nilai throughput terendah adalah pada saat jam 08.00 WIB sebesar 0,12 Mbps. Grafik menampilkan adanya kesesuaian antara hasil pengukuran nilai throughput dengan hasil pengukuran delay, dimana ketika delay paling tinggi yaitu pada jam 08.00 WIB maka nilai throughput terendahpun terdapat pada jam 08.00 WIB. Terlihat adanya kesinambungan antara delay dan throughput, dimana ketika delay tinggi maka throughput akan turun.

\section{Kesimpulan}

Dari hasil pengujian dapat diambil beberapa kesimpulan yaitu sistem layanan video streaming berhasil menampilkan video-video hasil streaming dari server, baik pada layanan video streaming maupun CCTV dan memenuhi standar ITU-T G.1010.

Pada pengukuran delay dari keempat skenario penggunaan layanan diperoleh nilai delay tertinggi pada saat pengujian adalah sebesar 195,09 ms sementara penggunaan terbaik dengan nilai delay terendah adalah sebesar 10,37 ms. Pada pengukuran delay pada penggunaan layanan dengan beberapa pengguna aktif terlihat bahwa semakin banyak jumlah pengguna aktif maka nilai delay semakin tinggi.

Pada pengukuran packet loss dari keempat skenario penggunaan layanan diperoleh nilai packet loss tertinggi pada saat pengujian adalah sebesar 5,22 \% sementara penggunaan terbaik dengan nilai packet loss terendah adalah sebesar $0 \%$. Pada pengukuran packet loss pada penggunaan layanan dengan beberapa pengguna aktif didapat bahwa semakin banyak jumlah pengguna aktif maka nilai packet loss semakin tinggi.

Pada pengukuran throughput dari keempat skenario penggunaan layanan diperoleh nilai throughput tertinggi pada saat pengujian adalah sebesar 0,82 Mbps sementara penggunaan terbaik dengan nilai throughput terendah adalah sebesar 0,06 Mbps. Pada pengukuran throughput terlihat adanya kesinambungan antara delay dan throughput, yaitu ketika delay tinggi maka throughput akan turun.
Hasil pengukuran kualitas layanan berdasarkan parameter delay, packet loss, dan throughput untuk layanan video streaming dan CCTV masih dalam kategori baik dan layak digunakan karena hasil pengukuran memenuhi standar berdasarkan ITU-T G.1010.

\section{Referensi}

[1]. Prasetyo, Aldy, Analisis dan Implementasi Beewatch (Internet-TV BINUS) Berbasiskan Red5 Server, Skripsi S-1, Binus, Jakarta, 2009.

[2]. Fahrurozi, Muhammad, Perancangan Dan Implementasi Video Streaming Berbasis Html 5 Pada Mesin Virtual, Skripsi S-1, UMS, Surakarta, 2014.

[3]. Nugraha, Firman Setya, Perencanaan dan Implementasi Virtual Local Area Network untuk Komunikasi Video Streaming dan Suara, JTET Vol. 3 No. 1 April 2014.

[4]. Iqbal, Perancangan Mesin Virtual Menggunakan Vmware Untuk Optimalisasi Server Pada Pt. Concord Consulting Indonesia, Jurnal Ilmu Komputer Vol. 9 No.1, Maret 2013.

[5]. Diharso, Adi Setio, Analisa Perbandingan Performansi Video Streaming Antara Darwin Streaming Server Dengan Red5, Skripsi S-1, Telkom University 2013.

[6]. Proxmox Server Solution, Proxmox Virtual Enviroment Datasheet,

http://www.proxmox.com/downloads/proxmoxve/misc/116-proxmox-ve-datasheet/download, Proxmox Server Solution GmbH, Vienna, 2013.

[7]. Kurniawan, Agus, Network Forensics Panduan Analisis dan Investigasi Paket Data Jaringan menggunakan Wireshark, ANDI, Yogyakarta, 2012.

[8]. Kristanto, Andri, Jaringan Komputer, Graha Ilmu, Yogyakarta, 2003.

[9]. Monfort, Jean-Yves, Basic Requirement to Quality of Service (IP centric), Workshop on Standardization EHealth, Swiss, 2003.

[10]. Nanda, S. and T. Chiueh, A Survey On Virtualization Technologies, Stony Brook University, Research Preliminary Exam Report, Brookhaven, New York, 2005.

[11]. Sofana, Iwan, CISCO CCNA \& Jaringan Komputer, Informatika, Bandung, 2012.

[12]. Szigeti, Tim. Christina Hattingh, End-to-End QoS Network Design: Quality of Service in LANs, WANs, and VPNs, Cisco Press, Amerika Serikat, 2004. 